knees, but could walk short distances without it.

Discussion. In 1943 Moore and Bohlman reported a patient with a giant-cell tumour of the upper end of the femur which was treated by local resection and a vitallium implant, but follow-up lasted only 2.5 years, because the patient died from cardiac failure. Our follow-up of the first operation of this type to be performed in the UK spans 43 years. Each of the implants had a cuff to receive the upper end of the remaining femoral shaft to improve fixation. Professor Zarek suggested that there should be three windows in the cuff to allow some blood supply to the femoral stump and this appears to have been successful. Two of the revisions were due to falls, but on each occasion the limb was salvaged by an enthusiastic approach with expert technical support.

We wish to thank Mr Maurice Down, OBE, and Professor J. Zarek for all their help.

No benefits in any form have been received or will be received from a commercial party related directly or indirectly to the subject of this article.

\section{REFERENCES}

Bingold AC. Prosthetic replacement of a chondrosarcoma of the upper end of the femur: eighteen-year follow-up. J Bone Joint Surg [Br] 1972;54-B:139-42.

Moore AT, Bohlman HR. Metal hip joint: a case report. J Bone Joint Surg 1943;25:688-92.

\title{
RECURRENT LOCKING OF THE WRIST DUE TO DORSAL MIDCARPAL SUBLUXATION
}

\section{A. C. CRAIGEN}

Midcarpal instability of the wrist is uncommon in the absence of injury and is extremely rare in children (Gerard 1980; Johnson and Carrera 1986; Lichtman et al 1993). Patients with ligamentous damage to the wrist often complain of a painful click or clunk, but true locking is rare and has been reported only as a result of loose bodies (Needoff and Frostick 1994; Ono et al 1994). We describe a child who presented with a locked wrist due to dorsal subluxation of the midcarpal joint.

Case report. A ten-year-old girl complained of a 'dislocated right thumb', but there had been no injury. She reported eight previous episodes, always when asleep or

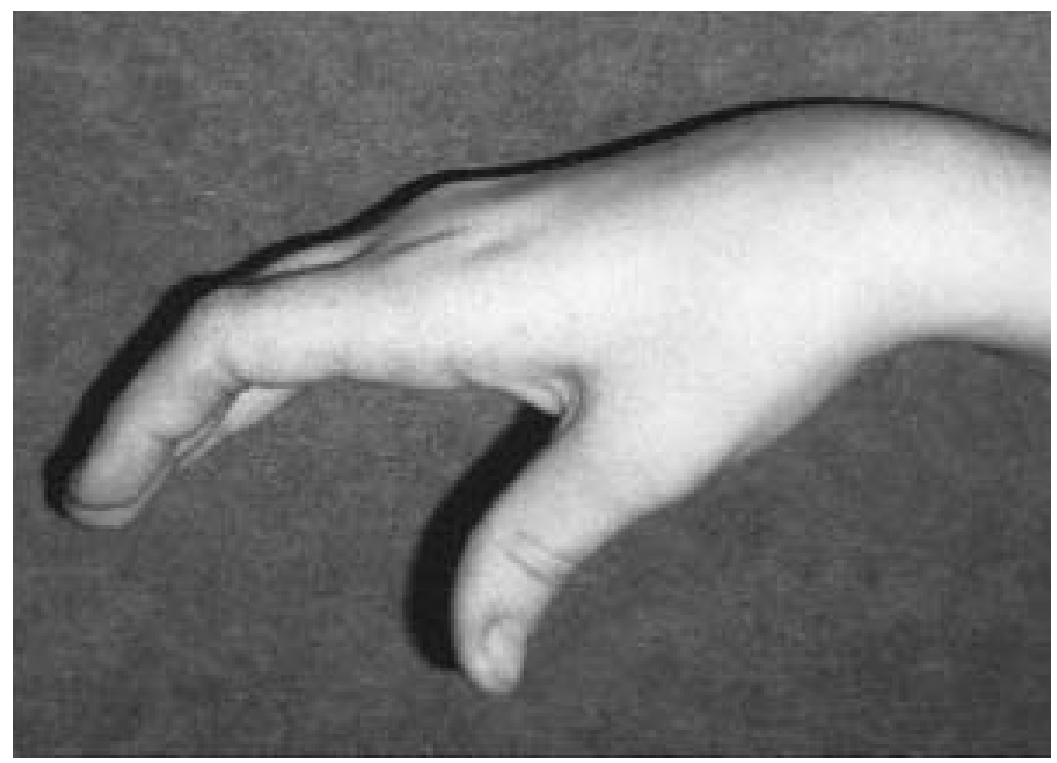

Fig. 1

M. A. C. Craigen, FRCS Ed, FRCS Orth, Senior Lecturer in Hand Surgery and Orthopaedic Trauma

Department of Orthopaedic and Accident Surgery, University Hospital, Queen's Medical Centre, Nottingham NG7 2UH, UK.

(C)1996 British Editorial Society of Bone and Joint Surgery 0301-620X/96/4R68 \$2.00

J Bone Joint Surg [Br] 1996;78-B:664-6.

Received 8 August 1995; Accepted after revision 10 November 1995 just going to sleep. On two occasions she had attended hospital but the 'dislocation' had reduced before radiographs had been taken. The previous episodes had been relieved by movement, which had caused reduction with a loud clunk. One similar episode had involved her left shoulder locking in internal rotation but had resolved with a clunk after passive external rotation by her mother. 

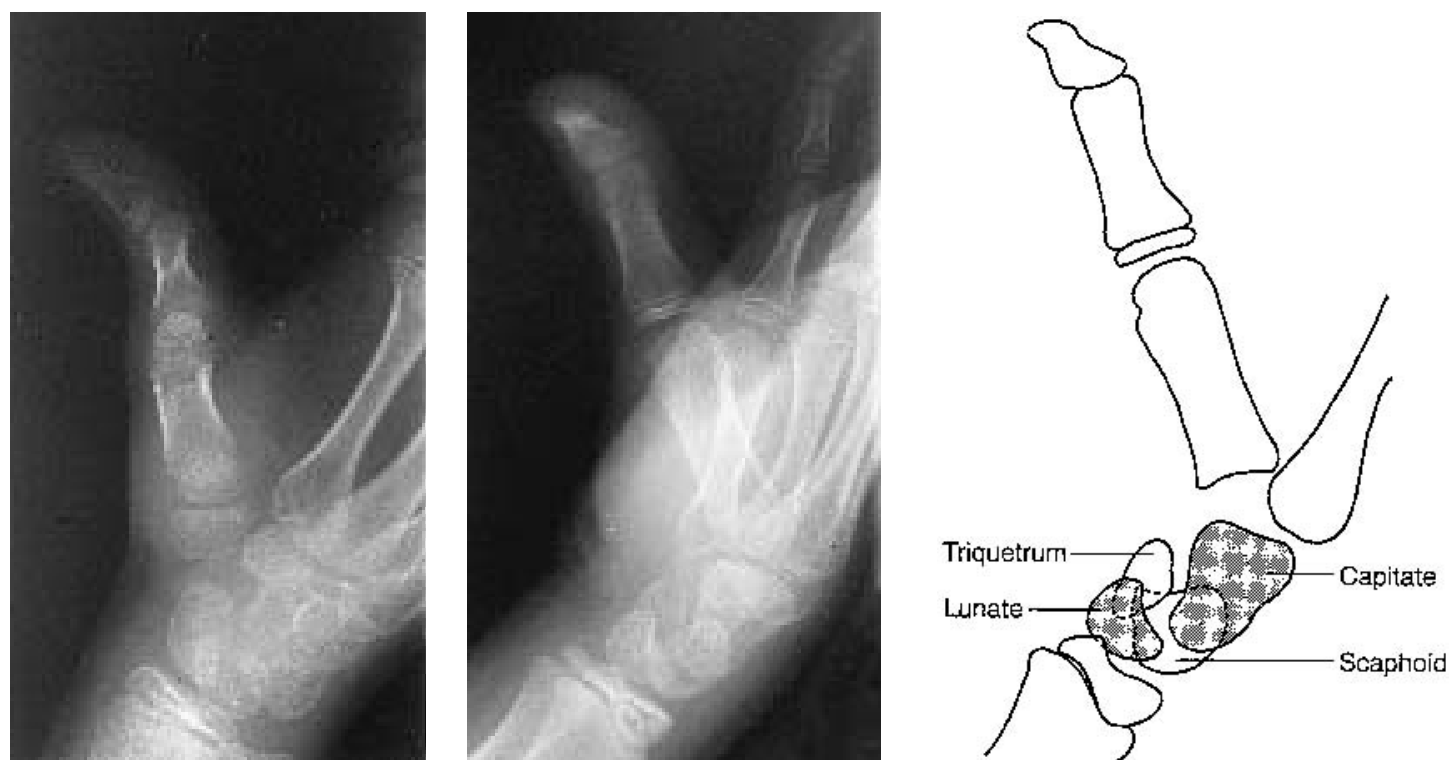

Fig. 2

The wrist was held in volar flexion of about $30^{\circ}$ with the thumb hyperextended at the interphalangeal joint (Fig. 1). Further volar flexion was possible but there was a solid block to dorsiflexion. Flexion of the thumb produced pain over the dorsum of the wrist. There was tenderness over the base of the thumb, but no soft-tissue swelling. She had clinical evidence of marked ligamentous laxity.

Radiography showed dorsal subluxation at the midcarpal joint (Fig. 2). Gentle manipulation of the wrist into dorsiflexion produced a clunk over the wrist and restoration of full movement, and radiographs showed reduction of the subluxation (Fig. 3). A scaphoid cast was applied for two weeks; further radiographs including stress views showed no evidence of instability. A wrist splint was provided to be worn at night, but further episodes occurred after removal of the cast. Cinéradiography under anaesthesia showed that the subluxation could be reproduced by dorsal stress on the wrist. After this, immobilisation in a scaphoid cast for six weeks and counselling of the mother on the possibility of habitual subluxation reduced the number of episodes.

Discussion. Instability of the midcarpal joint of the wrist usually occurs after injury associated with damage to the triquetrolunate or scapholunate joints. Ligamentous injuries to the wrist are very rare in children; the pattern of subluxation in our case has not previously been described (Gerard 1980), but is similar to the central carpal instability described by Johnson and Carrera (1986) in adults. In these, subluxation of the scaphocapitate joint was shown on stress testing under fluoroscopy. Their patients had clear histories of injury, complained of weakness and clicking of the wrist, and were unable to lift heavy objects. None had locking of the wrist or subluxation on static radiography.

Our case demonstrates the difficulties of diagnosing wrist instability. Having attention drawn to the thumb was initially confusing; this was probably due to bowstringing of the extensor pollicis longus tendon over the subluxed

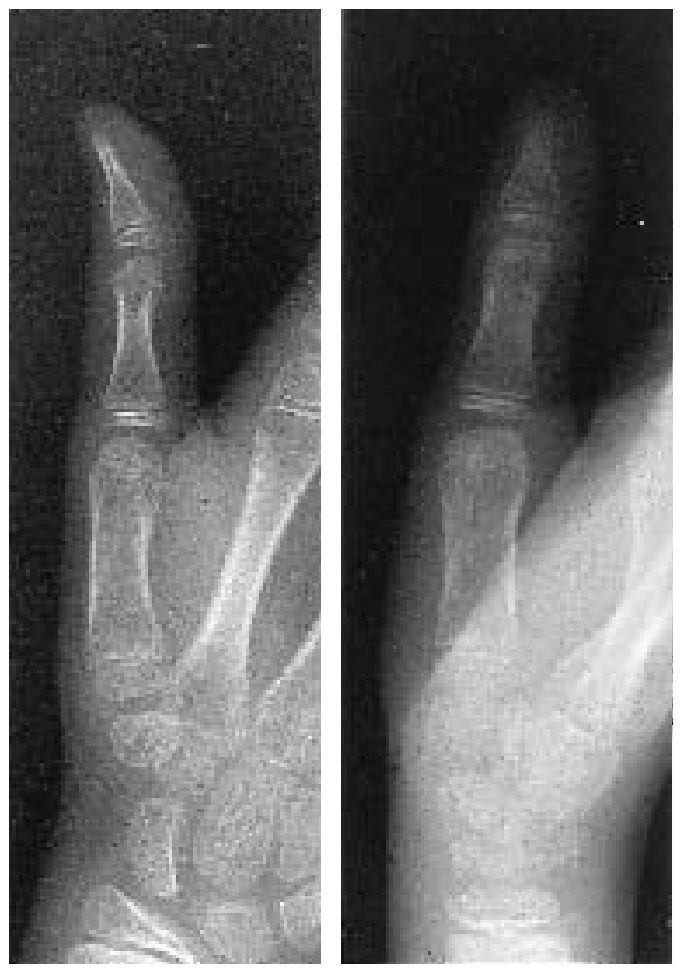

Fig. 3

capitate. Johnson and Carrera (1986) have shown that cinéradiography is often required to show the pathology, and is particularly useful in patients with a clunk or click since it may be possible to pinpoint the type of instability and thus the site of ligamentous damage. Wrist arthroscopy may also be useful.

In our patient the episodes always occurred at night and it is likely that muscle relaxation combined with marked ligamentous laxity allowed subluxation. The repeated episodes and the episode of possible shoulder subluxation as 
well as the minimal pain, swelling and swift return of range of movement suggested that the subluxation could be habitual. It remains to be seen whether the natural decrease in ligamentous laxity with age will prevent long-term symptoms.

The author would like to thank Mr I. T. A. Jeffrey, FRCS, for permission to report this patient.

No benefits in any form have been received or will be received from a commercial party related directly or indirectly to the subject of this article.

\section{REFERENCES}

Gerard FM. Post-traumatic carpal instability in a young child: a case report. J Bone Joint Surg [Am] 1980;62-A:131-3.

Johnson RP, Carrera GF. Chronic capitolunate instability. J Bone Joint Surg [Am] 1986;68-A:1164-76.

Lichtman DM, Bruckner JD, Culp RW, Alexander CE. Palmar midcarpal instability: results of surgical reconstruction. J Hand Surg 1993;18-A:307-15.

Needoff M, Frostick SP. Pisotriquetral loose body: an unusual cause of wrist pain. J Hand Surg Br 1994;19:215-6.

Ono H, Yajima H, Fukui A, Tamai S. Locking wrist with synovial chondromatosis: report of two cases. J Hand Surg Am 1994;19: 797-9.

\section{IDIOPATHIC OSTEOLYSIS OF THE ACETABULUM: A CASE REPORT}

\section{BORIS NEMEC, DAMIR MATOVINOVIĆ, GORDAN GULAN, SLAVKO KOZIĆ, TEA SCHNURRER}

Primary idiopathic osteolysis (Gorham's disease) is rare. It is characterised by the spontaneous onset of bone resorption without a known cause. Bones which previously appeared normal begin to resorb, partially or completely. Sometimes only a thin shell of cortical bone remains, and there is usually little replacement by fibrous tissue (Cannon
1986). This process can continue for years but in some cases stops spontaneously. The result of this osteolysis is deformity and impaired function (Hardegger, Simpson and Segmueller 1985). Cannon (1986) discusses the aetiopathology of Gorham's disease, but the exact mechanism of the osteolysis is still unknown.

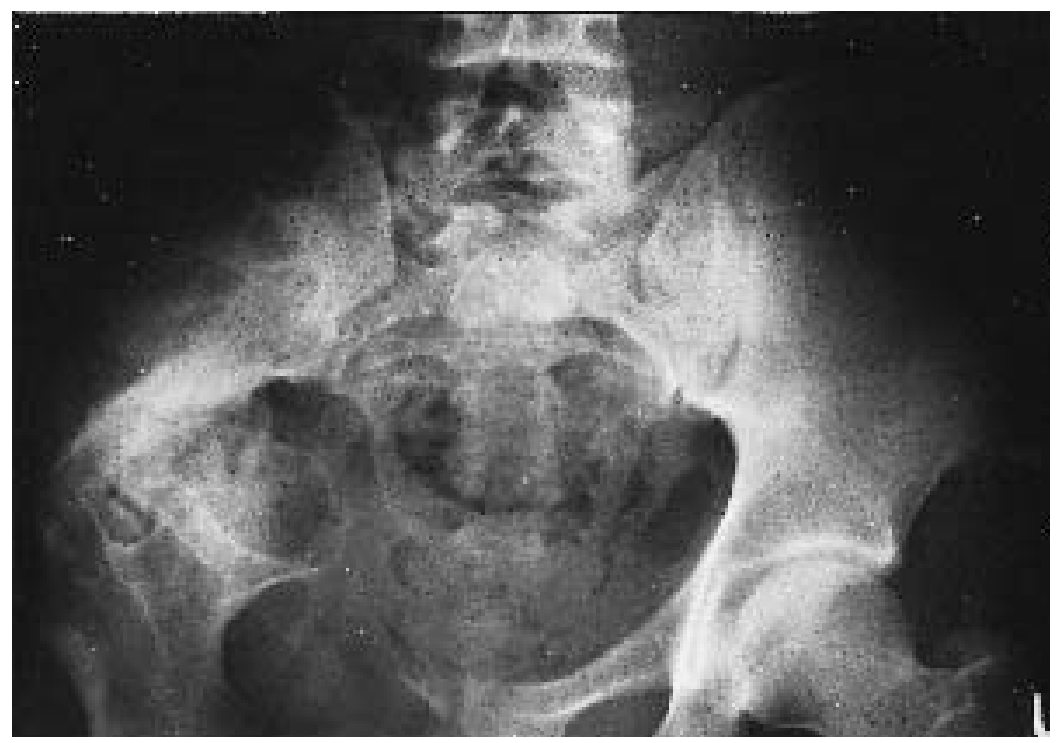

Fig. 1

B. Nemec, PhD, Orthopaedic Surgeon

D. Matovinović, PhD, Orthopaedic Surgeon

G. Gulan, MD, Fellow in Orthopaedic Surgery

S. Kozić, MD, Orthopaedic Surgeon

T. Schnurrer, MD, Fellow in Orthopaedic Surgery

Clinic for Orthopaedic Surgery, M. Tita 1, Lovran 51415, Croatia.

Correspondence to Dr B. Nemec.

(C)1996 British Editorial Society of Bone and Joint Surgery 0301-620X/96/4R71 \$2.00

J Bone Joint Surg [Br] 1996;78-B:666-7.

Received 26 October 1995; Accepted 5 December 1995
Spontaneous idiopathic osteolysis was first reported by Jackson in 1838, and since then a number of cases have been published under a wide variety of names which include acute spontaneous absorption of bone (Branch 1945), massive osteolysis (Gorham et al 1954), phantom bone (Gorham and Stout 1955) and disappearing or vanishing bones (Milner and Baker 1958). In some forms of the disease malignant nephropathy can occur (Torg and Steel 1968). 